\title{
Cortes irrumpidas. La judicialización conservadora del aborto en Argentina
}

Recibido: 23 de julio 2018

Revisado: 7 de agosto 2018

Aprobado: 14 de agosto 2018

María Eugenia Monte Argentina. Doctora en Derecho y Ciencias Sociales por la Facultad de Derecho de la Universidad Nacional de Córdoba. Becaria postdoctoral del Consejo Nacional de Investigaciones Científicas y Técnicas (CONICET). Sus áreas de investigación comprenden el estudio de las relaciones entre el género, la sexualidad y el derecho

en el marco de la política sexual feminista contemporánea. Integra

el Programa de Derechos

Sexuales y Reproductivos de la Facultad de Derecho de la Universidad Nacional de Córdoba (FD, UNC), y es profesora de la FD, UNC.

Correo electrónico: eugemonte@gmail.com

Juan Marco Vaggione Argentino. Profesor Titular de Sociología e Investigador del Consejo Nacional de Investigaciones Científicas y Técnicas (CONICET) en la Facultad de Derecho de la Universidad Nacional de Córdoba (UNC). Doctor en Derecho por la UNC y Doctor en Sociología por la New School University. Sus áreas de investigación incluyen el papel de las religiones en la esfera pública y el análisis de la política sexual contemporánea. Actualmente dirige el Programa en Derechos Sexuales y Reproductivos de la Facultad de Derecho (UNC). Correo electrónico: juanvaggione@yahoo.com
Resumen: En Argentina, las luchas de los movimientos de mujeres, feministas y LGBTI por reformar el derecho lograron disputar el orden sexual conservador sostenido por el poder religioso e imbricado en el discurso jurídico. Estos procesos de reforma, sin embargo, son resistidos por el activismo religioso conservador en diferentes instancias institucionales con el propósito de (re) instituir la moral religiosa conservadora en el derecho. En este trabajo focalizamos en las intervenciones de las ONGs y abogados autodenominados pro-vida en procesos judiciales en las cortes con el propósito de obstruir, impedir y/o criminalizar el acceso al aborto no punible en el país. El estudio de estos procesos nos permite ampliar la comprensión de una de las principales estrategias del conservadurismo religioso en América Latina, el uso del litigio para resistir las reformas legales progresistas.

Palabras clave: conservadurismo religioso; organizaciones pro-vida; judicialización; política sexual; aborto

\section{Burst Courts. Abortion Conservative Judicialization in Argentina}

Abstract: In Argentina, the women's, feminist and LGBTI movements struggle to reform the law managed to dispute the conservative sexual order sustained by religious power and imbricated in the legal discourse. These reform processes, however, are resisted by conservative religious activism in different institutional instances with the purpose of (re) instituting conservative religious morality in the legal discourse. This article focuses on the interventions of pro-life NGOs and lawyers in the judicial processes with the purpose of obstructing, preventing and / or criminalizing access to abortion in Argentina. The study of these processes allows us to expand the understanding of one of the main strategies of religious conservatism in Latin America, the use of litigation to resist the current legal reforms.

Key words: religious conservatism; pro-life; organizations; judicialization; sexual politics; abortion 
1. La sigla refiere al movimiento de personas lesbianas, gays, bisexuales, travestis, transexuales e intersex.

\section{Introducción}

En las últimas décadas, las luchas de los movimientos de mujeres, feministas y LGBTI ${ }^{1}$ en América Latina han logrado instalar con mayor intensidad cuestiones relacionadas con el cuerpo sexuado, provocando profundos cambios sociales, políticos y jurídicos (Vaggione 2012). Entre otras manifestaciones en este sentido se pueden mencionar una serie de reformas jurídicas relacionadas con la sexualidad, la reproducción y el parentesco. Aunque de manera heterogénea y con resultados diferentes, la mayoría de los países de la región debaten una serie de derechos relacionados con la provisión y distribución de anticonceptivos, la educación sexual en los colegios, las parejas del mismo sexo o la despenalización del aborto, entre otros.

La lucha de estos movimientos por reformar el sistema jurídico implica confrontar el poder de las principales religiones, particularmente los sectores conservadores católicos y evangélicos. Las religiones han tenido, y continúan teniendo, un impacto determinante sobre las formas de regular el orden sexual. En particular, el impacto del catolicismo en la región ha matrizado al derecho sentando las fronteras entre lo legal e ilegal en relación con las identidades y prácticas vinculadas a la sexualidad. No resulta extraño, entonces, que las luchas por reformar derechos relacionados con la sexualidad y la reproducción sea principalmente resistidas por la jerarquía religiosa en defensa de un orden moral restrictivo de la libertad y la diversidad sexual.

Sin embargo, junto a este papel histórico de las jerarquías religiosas conservadoras han comenzado a tener cada vez un mayor protagonismo sectores de la sociedad civil que bajo el rótulo de organizaciones no gubernamentales (ONGs) autodenominadas pro-vida proponen estrategias para impactar en el derecho. El impacto de los movimientos de mujeres, feministas y LGBTI también ha generado importantes mutaciones en las formas de oposición de los sectores religiosos conservadores. Estas ONGs defienden la misma agenda conservadora que la jerarquía religiosa, pero lo hacen de formas novedosas. En distintos países es cada vez más frecuente observar la centralidad de estas ONGs que, liderando la resistencia a la política feminista, participan de los principales debates públicos, intervienen como especialistas e inician procesos judiciales, entre otras estrategias.

Argentina no es una excepción a la complejización de la política sexual contemporánea. Por un lado, los movimientos de mujeres, feministas y LGBTI han logrado, durante las últimas décadas, modificar el derecho para garantizar, al menos formalmente, la provisión y distribución de anticonceptivos, la educación sexual integral, el matrimonio para las parejas del mismo sexo, la identidad de género auto-percibida, entre otras. Por otro lado, en cada uno de estos debates jurídicos es posible observar las mutaciones del activismo religioso conservador en resistencia a estas reformas. Junto a las jerarquías 
religiosas y a los argumentos morales, comenzaron a visibilizarse una serie de actores laicos y argumentos científicos y jurídicos. En particular, es notable el aumento y la activación de abogados pertenecientes a ONGs pro-vida y pro-familia como una faceta de la política sexual conservadora.

El aborto es, sin dudas, el tema que condensa con mayor intensidad esta compleja dinámica en Argentina (como en la mayoría de los países). Desde la reforma constitucional de 1994, aunque incrementalmente desde 2000, el aborto ha sido uno de los ejes centrales de los debates feministas y de la oposición religiosa conservadora. Precisamente, el propósito de este trabajo es analizar la oposición del activismo religioso conservador, particularmente el accionar de ONGs y abogados pro-vida, en procesos judiciales de aborto no punible con posterioridad al año 2005, año en que se conformó la Campaña Nacional por el Derecho al Aborto Legal Seguro y Gratuito -de ahora en más, la Campaña. ${ }^{2}$ Este es un momento relevante porque potenció las estrategias feministas para garantizar el acceso a los abortos no punibles. ${ }^{3}$

Asumimos que la maximización del discurso jurídico así como la búsqueda de impactos en las instituciones jurídico estatales de las ONGs y los abogados pro-vida forman parte de un proceso más amplio de mutación de las estrategias de resistencia religioso-conservadoras a la política sexual feminista en las que el derecho devino en un sitio privilegiado de disputas (Smart 1989). Nos preguntamos cómo el derecho es ejercido materialmente en prácticas de resistencia históricas, contingentes y situadas en las cortes (García Romanutti 2015) que sostienen, modifican o introducen una imbricación entre la moral religiosa y el discurso jurídico.

El artículo está dividido en tres secciones para indagar las intervenciones de las ONGs y abogados pro-vida en procesos judiciales de aborto no punible. La primera sección busca introducir algunos aspectos de la articulación entre derecho secular y doctrina religiosa que caracterizan las regulaciones jurídicas sobre la sexualidad en la región. En particular, proponemos el concepto de imbricación para captar el impacto determinante de lo religioso sobre las formas de regular la sexualidad, la reproducción y el parentesco. Consideramos que es necesario entender el papel de estas ONGs y abogados pro-vida como una reacción al quiebre o fisura de esta imbricación logrado, particularmente, por el impacto de los movimientos de mujeres, feministas y LGBTI.

En la segunda sección profundizamos sobre el proceso de emergencia y movilización de las ONGs pro-vida en Argentina. Como lo han considerado investigaciones previas (Morán Faúndes et al., 2015), estas organizaciones emergen en respuesta ( $y$ de algún modo en mímesis) al avance e impacto de las demandas de los movimientos de mujeres, feministas y LGBTI en la arena pública y jurídica. Una de las características de estas ONGs es ser parte de procesos judiciales para impedir o revertir la vigencia de derechos relacionados con la sexualidad y la reproducción. Finalmente, en la última sección, la más extensa del artículo, analizamos las formas en que estas ONGs y abogados pro-vida han judicializado el aborto no punible en Argentina, con el
2. Un estudio sobre la Campaña puede consultarse en Anzorena y Zurbriggen (2013).

3. En Argentina, el aborto practicado por una mujer y el aborto practicado a una mujer con o sin su consentimiento, aún sin el propósito de causarlo, está penalizado por el código penal desde 1921. Sin embargo, el mismo código establece situaciones en las que el aborto no es punible (riesgo para la salud de la mujer, riesgo para la vida de la mujer y violación). La

Campaña presentó un proyecto de reforma legal en el Congreso de la Nación en los años 2007, 2008, 2010, 2012, 2014, 2016 y 2018, recibiendo tratamiento en la última oportunidad conjuntamente con otros 8 proyectos de ley. El 14 de junio del 2018, un proyecto consensuado obtuvo media sanción en la Cámara de Diputados, aunque el 9 de agosto del 2018 esa media sanción fue rechazada por la Cámara de Senadores. 
propósito de profundizar el conocimiento sobre el activismo religioso conservador en las cortes.

\section{Estrategias de resistencias conservadoras a la política sexual feminista: el derecho como sitio de disputa}

La historia del derecho moderno es, en muchos sentidos, la historia de su au-

4. Una presentación general de la interrelación entre la religión y el derecho puede consultarse en la introducción de Sullivan et al. (2013) al libro After a Secular Law.

5. Más bien implicó la reinscripción de lo religioso en formas nuevas. En las últimas décadas, una significativa cantidad de investigaciones analizan críticamente las principales dimensiones y supuestos de la teoría de la secularización. El trabajo de Casanova (1994) se volvió un estudio clásico que desmantela esta teoría (tres sub-tesis) y provee una reflexión crítica de sus limitaciones. tonomización y separación de lo religioso. ${ }^{4}$ Sin embargo esta historia ha resultado más compleja y sinuosa de lo previsto, particularmente cuando se consideran las formas de regular la prácticas sexuales y reproductivas. La laicización del Estado, un componente clave de la modernidad, no necesariamente significó la eliminación de lo religioso del derecho estatal. ${ }^{5}$ Como se ha señalado en otras publicaciones, es posible identificar un proceso de imbricación entre lo religioso y lo secular en las regulaciones jurídicas estatales vinculadas a las decisiones y prácticas sexuales y/o los lazos de parentesco (Vaggione 2016). En América Latina, el derecho estatal tiende a montarse sobre la doctrina católica «transmutando» el pecado en delito y una moral particular en regulaciones universales.

La regulación jurídica de la sexualidad constituye un dominio en el que la imbricación siempre contingente entre lo religioso y lo secular es, entonces, un aspecto determinante. Tanto el orden sexual contemporáneo como sus regulaciones han sido heredados, en gran parte, de las principales tradiciones religiosas. Esta es la razón por la cuál las regulaciones de la familia, el parentesco y la reproducción han estado y siguen estando imbuidas de cosmovisiones religiosas de forma tal que a menudo la distinción entre lo secular y lo religioso es en exceso problemática (Connolly 1999, Asad 2003). Este aspecto es relevante en América Latina donde la influencia de la Iglesia Católica ha dejado una matriz de inteligibilidad del orden sexual que va mucho más allá de lo religioso para impregnar la formación social y política en general.

Insistir entonces en una nítida distinción entre lo religioso y lo secular, más allá de su utilidad analítica, normativa y estratégica, puede implicar una simplificación y una proyección de fronteras ficticias. El reconocimiento de esta imbricación no implica ignorar que la distinción entre las normas religiosas y el derecho moderno se hizo más pronunciada a lo largo de los siglos XIX y XX. Sin embargo, además de rastrear la separación y la ruptura entre las regulaciones religiosas y el derecho moderno, también resulta necesario prestar atención a las continuidades y porosidades especialmente en América Latina, de fuerte raigambre de creencias, prácticas y rituales religiosos católicos, pero también de otras religiones como la evangélica (Connolly 1999, Douzinas 2000).

La política sexual contemporánea en América Latina puso en evidencia la porosidad entre las fronteras religioso-seculares en el derecho. Por un lado, en las luchas de los movimientos de mujeres, feministas y LGBTI por volver visi- 
ble la herencia religiosa solapada en las instituciones jurídico-estatales. Discutir el matrimonio igualitario, el acceso a anticonceptivos, la educación sexual y el aborto implica criticar las maneras en que el derecho secular ampara e invisibiliza la doctrina católica. Por ello, las demandas de estos movimientos conllevan una confrontación con el poder religioso. Uno de los principales impactos cuando se debaten los derechos relacionados con la sexualidad y la reproducción es criticar las formas en que el derecho estatal sostiene la doctrina católica.

Precisamente, uno de los efectos más profundos ( $\mathrm{y}$ menos estudiados) del movimiento por la LGBTI es haber logrado transformar la exigencia de la complementariedad de sexos en el matrimonio de un componente de la cultura (aceptado y naturalizado socialmente) a un resabio de la influencia católica inscripto en el derecho. Algo similar sucede cuando los movimientos de mujeres y feministas politizan al aborto puesto que logran, de alguna manera, no solo evidenciar el papel que el derecho penal tiene como discurso puramente moralizador del cuerpo de las mujeres, sino que incluso saca al aborto del constructo delito-pecado para incluirlo como parte de los derechos de las mujeres y de las personas gestantes en general.

Así como el mayor poder de la Iglesia Católica ha sido transmutar lo religioso en cultura (la cruz como un símbolo religioso a uno cultural, por ejemplo), una de las principales luchas de los movimientos de mujeres, feministas y LGBTI es volver a localizar como religioso aquello naturalizado (y escondido) bajo el manto de la cultura. Cuando estos movimientos logran el reconocimiento de derechos que amplían los márgenes de libertad para las prácticas relacionadas con el género, la sexualidad y la reproducción; también profundizan el proceso de secularización del derecho, esto es, el proceso de des-imbricación de restos religiosos esencialistas, dogmáticos y conservadores del discurso jurídico estatal.

Por otro lado, la resistencia religioso-conservadora busca oponerse a este proceso de profundización de la desimbricación del derecho. Aunque los sectores conservadores son heterogéneos defienden, en su mayoría, una concepción de la moral sexual emparentada con las tradiciones católicas y evangélicas. Sin embargo, esta defensa se lleva adelante por parte de actores y discursos renovados para potenciar su impacto. Una vez interrumpido el poder hegemónico de la Iglesia Católica que mantiene oculta la imbricación entre lo religioso y lo secular en el derecho, la reacción religioso-conservadora se articula desde la sociedad civil y esgrime argumentos científicos, bioéticos y jurídicos en defensa de un orden sexual reproductivista.

Efectivamente, una de las principales formas del activismo conservador para revertir el proceso de secularización del derecho es la juridificación de su resistencia. Como lo hemos analizado previamente, existe un proceso de secularismo estratégico del activismo religioso conservador, por el cual comienza a utilizar y/o a generar argumentos jurídicos para confrontar los derechos vinculados a la sexualidad y la reproducción (Vaggione 2016). Así, la oposición a las demandas feministas y LGBTI se canaliza, cada vez con mayor intensi- 
dad, a través de la apelación al discurso de derechos y de la intervención en instituciones jurídico-estatales como las legislaturas, el Congreso y en procesos judiciales en las Cortes.

Considerar el entramado de las cosmovisiones religiosas con el derecho moderno, por lo tanto, presenta desafíos al momento de estudiar las estrategias de resistencia religioso-conservadoras a la política feminista, y exige marcos referenciales socio-jurídicos que habiliten indagaciones sobre las prácticas de resistencia jurídica que excedan aquellos que asumen que el derecho estatal posibilita la liberación o enmascara la opresión para abordarlo como un sitio institucionalizado de disputas en el que se producen otras formas de saber (Smart 1989, 7, 88, 138-139). Siguiendo esta línea, entendemos que las prácticas jurídicas que constituyen los procesos judiciales suponen la producción de saberes posibilitados por relaciones de poder institucionalizados formalmente en las cortes. El discurso jurídico, entonces, se configura en relación a otros discursos, y relaciones de poder definidos históricamente. Dicho de otra manera, el estudio del discurso como es producido por prácticas jurídicas permite mostrar el rasgo situado del discurso, esto es, situado en relación a otras prácticas jurídicas discursivas, así como en relación a prácticas jurídicas no discursivas -relaciones, institucionalidad, regulaciones, rituales (Foucault 2008).

Precisamente, el propósito de este trabajo es indagar en las estrategias de resistencia religioso-conservadoras situadas en procesos judiciales de aborto no punible. Nos preguntamos cómo el derecho es ejercido materialmente en prácticas de resistencia históricas, contingentes y situadas en las cortes (García Romanutti 2015) y de qué forma se imbrican discursos religiosos-seculares en estas prácticas para instituir una política sexual conservadora.

\section{Las ONGs pro-vida en Argentina. Política, sexualidad y reproducción en las instituciones jurídico-estatales}

El impacto de los movimientos de mujeres, feministas y LGBTI en América Latina ha dado lugar a un proceso de politización reactiva (Vaggione 2005, 240-43), que explica las principales mutaciones socio-políticas de lo religioso en las democracias contemporáneas. Esta politización se caracteriza por dos rasgos específicos. En primer lugar, un creciente secularismo estratégico (Vaggione 2005, 240), que implica el desplazamiento de discursos religiosos a discursos científicos, bioéticos y jurídicos; y supone una estrategia de reducción de discursos religiosos y una maximización de discursos seculares para penetrar espacios que difícilmente podrían ser permeados por un discurso explícitamente religioso.

En segundo lugar, una intensificación y diversificación en la existencia de ONGs autodenominadas pro-vida y/o pro-familia, que sostienen una concepción monogámica, heterosexual y reproductiva de la sexualidad en oposición 
a la política sexual feminista en espacios sociales, políticos e institucionales (Vaggione 2005; González Ruiz 2006; Mujica 2007). Si bien la existencia de ONGs de corte religioso no es una novedad, estas no sólo han crecido en número, sino que han comenzado a liderar, en ámbitos nacionales y transnacionales, la defensa de la criminalización del matrimonio heterosexual y/o del aborto, entre otros aspectos de la política contemporánea.

La literatura especializada (Morán Faúndes 2015; Morán Faúndes et al. 2015) señala que en Argentina pueden identificarse distintas etapas respecto al tipo de ONGs autodenominadas pro-vida. Si bien existen antecedentes de conformación de organizaciones similares en la primera mitad del siglo XX (como el Consorcio de Médicos Católicos, Buenos Aires, 1929; y la Corporación de Abogados Católicos, Buenos Aires, 1935), las primeras ONGs pro-vida se establecieron durante la década de 1980 y principios de 1990. Estas organizaciones estuvieron fuertemente atravesadas por la retórica de la jerarquía vaticana y se presentaban públicamente como católicas.

Así, durante la década de 1980 y principios de la década de 1990, las agrupaciones como Pro Familia (Buenos Aires, 1983), Grávida (Buenos Aires, 1989), Fundación Argentina del Mañana (Buenos Aires, 1989), Pro Vida San Luis (San Luis, 1989) y Portal de Belén (Córdoba, 1991) fueron creadas con el fin de defender una política sexual conservadora. En términos generales, las ONGs conformadas en estos años intentaron defender su posición mediante la búsqueda de impactos socioculturales y la provisión de servicios asistenciales en sectores poblacionales específicos y tuvieron al aborto como su temática principal (Morán Faúndes et al. 2015).

Desde mediados de la década de 1990 hasta la década del 2000 emergieron ONGs pro-vida que tuvieron entre sus estrategias impactar en el ámbito institucional-estatal -como las legislaturas o el Congreso y las cortes- e, incluso, en el ámbito internacional, en asuntos relacionados con la sexualidad y la reproducción. Tal es el caso de la organización Familias del Mundo Unidas por la Paz (Buenos Aires, 1994), Pro Vida (Buenos Aires, 2000) y Fundación 25 de Marzo (Córdoba, 2002). También algunas de las organizaciones conformadas a finales de 1980 y principios de 1990 reorganizaron sus estrategias para poder incidir en la política institucional-estatal de diversas maneras (Morán Faúndes et al. 2015).

Esta literatura pone en evidencia el carácter dinámico del activismo religioso conservador. Las ONGs pro-vida no sólo son una reacción a la política sexual feminista, sino que van adaptando sus estrategias y discursos. La politización reactiva que caracteriza a los sectores religiosos conservadores se observa también en las estrategias utilizadas por las ONGs pro-vida para oponerse a los derechos que amplían los márgenes de libertad relacionados con la sexualidad y la reproducción. Entre estas estrategias cobraron trascendencia las intervenciones en procesos judiciales en las cortes, que tienen su antecedente en el proceso judicial sobre anticoncepción iniciado por la ONG pro-vida Portal de Belén en el año 1998 (Peñas Defago y Morán Faúndes 2014). 
En la próxima sección nos concentramos en las intervenciones de ONGs y abogados pro-vida en procesos judiciales de aborto no punible, asumiendo que la estrategia de maximización del discurso jurídico (Vaggione 2005) forma parte de un proceso más amplio de juridificación de las estrategias de resistencia religioso-conservadoras. Entendemos por juridificación la apropiación de discursos ligados al derecho y a la ciudadanía, así como una apelación a las instituciones jurídicas estatales para dirimir asuntos políticos (Domingo 2009, 35). Este proceso se pone en evidencia en la judicialización del conservadurismo religioso del aborto no punible.

\section{Judicialización conservadora del aborto no punible}

Las luchas de los movimientos de mujeres y feministas sobre la regulación jurídica de aborto se situaron en diferentes espacios jurídico-estatales en los que tuvieron como propósito, incrementalmente desde la conformación de la Campaña en el 2005, generar condiciones para el acceso al aborto no punible en el sistema de salud (Bergallo 2011). Esto comprendió disputas en procesos en las cortes, en las legislaturas y los ministerios de salud, en situaciones en que niñas, jóvenes y mujeres reclamaron acceder a la práctica del

6. Identificamos procesos judiciales de aborto no punible en los que participaron organizaciones del movimiento de mujeres y feministas frente a resistencias conservadoras en las Cortes que tuvieron determinados efectos políticos en una base de datos construida a partir de búsquedas en revistas jurídicas especializadas, en los medios de prensa escrita nacionales y entrevistas en profundidad a referentes del feminismo jurídico nacional.

7. En este trabajo identificamos los procesos judiciales por el primer nombre que aparece en su identificación judicial -generalmente son las iniciales de la persona quien inicia el proceso judicial y a la que se refiere con iniciales para resguardar la identidad- y con independencia de cómo se lo identifique en la literatura especializada. En algunos procesos judiciales, la identificación del proceso coincide con las iniciales de los nombres de las niñas, jóvenes y mujeres involucradas. aborto no punible, y en relación a los protocolos de atención de abortos no punibles que regulan el procedimiento para la realización de la práctica del aborto en el sistema de salud, o la provisión de los medicamentos necesarios.

Así como en otros procesos de reforma legal, aquí también estuvo presente el activismo de ONGs y abogados pro-vida (Morán Faúndes et al. 2011). Desde el 2006, es posible advertir presentaciones en procesos judiciales de aborto no punible ${ }^{6}$ que implicaron el uso de recursos judiciales, la solicitud de medidas judiciales y la apelación a las cortes para dirimir asuntos relacionados con la extensión, constitucionalidad y convencionalidad de la regulación jurídica del aborto y con la realización de las prácticas del aborto no punible en diferentes provincias del país y en la ciudad de Buenos Aires. ${ }^{7}$ Estos procesos judiciales comprendieron la disputa por la realización de la práctica de aborto a niñas, jóvenes y mujeres, así como por los protocolos de atención de abortos no punibles, y la provisión de medicamentos.

Las presentaciones de ONGs y abogados pro-vida en procesos judiciales de aborto no punible tuvieron diferentes efectos en las decisiones judiciales, en las decisiones de los profesionales de la salud y en la experiencia de las niñas, jóvenes y mujeres involucradas. Asimismo, estos procesos judiciales de aborto no punible trascendieron las fronteras de la institucionalidad estatal puesto que, en la mayoría de estos procesos judiciales, las ONGs y abogados pro-vida los expusieron en los medios de prensa, en publicaciones, en encuentros colectivos y en reclamos callejeros; y tuvieron efectos materiales en luchas situadas en las cortes, en regulaciones jurídicas posteriores y en las prácticas de abortos no punibles. 
En base al análisis realizado de los distintos procesos judiciales de aborto no punible, identificamos dos tipos de judicialización conservadora que se profundizan a continuación. Como se puede observar, estas formas de judicialización conservadora son reactivas a los avances de la política feminista respecto al acceso al aborto no punible en el sistema de salud. En primer lugar, presentamos la judicialización conservadora destinada a imposibilitar el acceso de mujeres al aborto en casos de aborto no punible. En segundo lugar, analizamos la judicialización conservadora destinada a impugnar los protocolos de atención de abortos no punibles que garantizan el acceso de las personas gestantes a los abortos no punibles.

\section{Obstrucción, impedimento y criminalización de prácticas de aborto no punible}

Una de las ONGs que es parte de la judicialización conservadora de prácticas de abortos no punibles es la Corporación de Abogados Católicos fundada en el año 1935, y constituida como una asociación civil desde 1987. El estatuto establece que la Asociación Civil «Corporación de Abogados Católicos» tiene como finalidad «proveer al bien común mediante la asunción de los valores morales contenidos en la Doctrina y el Magisterio de la Iglesia Católica, intentando que estos regulen las acciones de los individuos y de la sociedad; defender y difundir (...) los principios de dicha doctrina (...); contribuir al mejoramiento del orden jurídico positivo sobre la base de los principios del Derecho Natural». ${ }^{8}$ Asimismo, el estatuto prevé brindar asesoramiento gratuito a personas carentes de recursos, y propender al afianzamiento de una buena administración de justicia. ${ }^{9}$ Esto la habilita jurídicamente a presentarse ante instituciones estatales como las cortes.

En el año 2004, la Corporación de Abogados Católicos, conjuntamente con el Consorcio de Médicos Católicos, efectuó una declaración criticando el «Procedimiento en casos de abortos no punibles» presentado en la legislatura de la ciudad de Buenos Aires: $;^{10}$ y en el año 2005, otra contra la sentencia de la Suprema Corte de Justicia de la provincia de Buenos Aires que resolvió favorablemente un proceso judicial en el que una mujer embarazada con una afección cardíaca había solicitado una autorización judicial para la realización de un aborto no punible en el sistema de salud. De acuerdo con los documentos de la organización, estas presentaciones fueron debido a que «han sucedido hechos de trascendencia jurídica que pusieron en tela de juicio valores morales y derechos naturales de la ciudadanía». ${ }^{11}$

Un año después, en el 2006, la joven L., M.R., embarazada como producto de un abuso sexual, solicitó la práctica del aborto no punible en el sistema de salud público de la ciudad de La Plata, provincia de Buenos Aires. Ante la solicitud intervinieron diferentes profesionales de la salud y el Comité de Bioética del hospital. Cuando la joven L., M.R. estaba por realizarse el aborto, una jueza de menores emitió una orden judicial en la que dispuso impedirlo. La decisión de la jueza fue confirmada por la Cámara de Apelaciones y revertida
8. Documentos de acreditación de la personería jurídica presentados por la Corporación de Abogados Católicos en el proceso judicial L., M.R., p. 507 del expediente judicial.

9. Documentos de acreditación de la personería jurídica presentados por la Corporación de Abogados Católicos en el proceso judicial L., M.R., pp. 507-508 del expediente judicial.

10. Documentos de acreditación de la personería jurídica presentados por la Corporación de Abogados Católicos en el procesos judicial L., M.R., p. 520 del expediente judicial.

11. Recurso extraordinario federal presentado por la Corporación de Abogados Católicos contra la sentencia de la Suprema Corte de Justicia de la provincia de Buenos Aires en el proceso judicial L., M.R., p. $525 \mathrm{del}$ expediente judicial. 
12. Recurso extraordinario federal presentado por la Corporación de Abogados Católicos contra la sentencia de la Suprema Corte de Justicia de la provincia de Buenos Aires en el proceso judicial L., M.R., pp. 525-526 del expediente judicial.
13. Documento judicial presentado por el rector de la Universidad Católica de La Plata ante la Suprema Corte de Justicia de la provincia de Buenos Aires en el proceso judicial L., M.R. para solicitar la designación de un defensor y patrocinante de la persona por nacer, pp. 496-504 del expediente judicial.

\section{Documento judicial} presentado por la Corporación de Abogados Católicos, en el que denuncia irregularidades ante la Suprema Corte de Justicia de la provincia de Buenos Aires en el proceso judicial L., M.R., pp. 553-555 del expediente judicial. por la Suprema Corte de Justicia de la provincia de Buenos Aires. Tras la sentencia de la Suprema Corte de Justicia de la provincia de Buenos Aires, la Corporación de Abogados Católicos presentó un recurso contra esta sentencia con el propósito de impedir la realización de la práctica.

En la presentación contra la sentencia de la Suprema Corte de Justicia de la provincia de Buenos Aires, la Corporación de Abogados Católicos invocó la representación de la persona por nacer, sostuvo que «es doctrina unánime y definitiva del Magisterio de la Iglesia Católica, la inviolabilidad de la vida humana inocente, desde el primer instante (...) cualquiera sean las circunstancias en que hubiere sido engendrada (...). Dicho esto para demostrar que claramente esta presentación entra de pleno en los fines de la Asociación», y fundamentó esto en la Encíclica Evangelium Vitae. ${ }^{12}$ El proceso judicial L., M. $R$. trascendió en los medios de prensa, fue acompañado por organizaciones del movimiento de mujeres y feministas, e integrantes de la Campaña.

Las declaraciones de la Corporación de Abogados Católicos contra el protocolo del 2004, la declaración contra un fallo favorable al acceso al aborto no punible del 2005, y la presentación en el proceso judicial L., M.R. en el 2006 ponen de manifiesto la fuerte defensa de un modelo jurídico de imbricación entre derecho y religión. En los documentos del proceso judicial, la organización evidencia una estrategia de separación mínima entre lo religioso y lo secular. Por un lado, desde su denominación y sus estatutos deja claro la imbricación identitaria entre abogado y católico. Es esta doble inscripción la que motiva su existencia como ONG. Por otro lado, su forma de justificar la presentación en el proceso judicial vuelve a imbricar aspectos religiosos y seculares, ya que cita para ello al Magisterio de la Iglesia y a una de las principales Encíclicas que contiene disposiciones contrarias al aborto.

Además de estas presentaciones en el proceso judicial L., M.R., la Corporación de Abogados Católicos conjuntamente con el rector de la Universidad Católica de La Plata ejercieron presiones a la familia de L., M.R y a los médicos en el hospital para que desistieran de la realización de la práctica, enviaron documentos intimidatorios a los profesionales de la salud del hospital donde procedería la realización de la práctica e hicieron públicas estas situaciones en los medios de prensa. El rector de la Universidad Católica de La Plata, además, se presentó en el proceso judicial en defensa de la persona por nacer. ${ }^{13}$ Los profesionales del sistema de salud se opusieron a realizar la práctica e informaron que, por lo avanzado del embarazo, no constituía un aborto sino un parto inducido. Luego, otros centros de salud del país también se negaron a realizar la práctica.

Esta fuerte negación a la realización de la práctica del aborto no punible provocó que esta se realizara en el circuito del aborto clandestino. Luego de la realización del aborto, la Corporación de Abogados Católicos presentó una denuncia para solicitar una investigación de las consecuencias penales de las actividades de funcionarios públicos, profesionales de la salud y personas que facilitaron la realización de este. Inscribió sus presentaciones en el discurso de los derechos humanos, especialmente los que protegen los derechos de los niños, niñas y adolescentes, y el derecho a la vida. ${ }^{14}$ Las sucesi- 
vas presentaciones de la judicialización conservadora de la Corporación de Abogados Católicos en el procesos judicial L., M.R. estuvieron destinadas a obstruir, impedir y criminalizar el aborto no punible, y comprendieron a todos los que la habilitaron en los espacios institucionales estatales sanitarios y judiciales. Con posterioridad a la realización de la práctica del aborto, además, un abogado católico presentó una denuncia como "víctima difusa» de los intereses protegidos por el código penal en los casos de homicidio. ${ }^{14}$

Lo que tienen en común las presentaciones de la Corporación de Abogados Católicos, del rector de la Universidad Católica de La Plata y del abogado católico es que eran ajenos al proceso judicial, que invocaron la defensa de la persona por nacer y que se inscribieron en el discurso de los derechos humanos, especialmente los que protegen los derechos de los niños, niñas y adolescentes, y el derecho a la vida. Asimismo, estas presentaciones estuvieron destinadas de diferentes formas a obstruir, impedir y criminalizar la práctica.

En un sentido similar, ese mismo año e inmediatamente después del proceso judicial L., M.R, la ONG pro-vida VITAM intervino en el proceso judicial, Ce Mendoza para practicarse un aborto no punible. VITAM inició un proceso judicial de amparo ${ }^{15}$ invocando la protección de intereses difusos y en el marco del cual solicitó una medida para suspender la práctica del aborto. La Cámara de Apelaciones admitió la medida y dispuso suspender la práctica, pero poco tiempo después la Suprema Corte de Justicia de la provincia de Mendoza revocó esta suspensión, y además resolvió que la ONG pro-vida carecía de legitimidad para intervenir en estos procesos judiciales. ${ }^{16}$ Finalmente, el aborto pudo concretarse. ${ }^{17}$

Al igual que la presentación de la Corporación de Abogados Católicos en el proceso judicial L., M.R., la ONG pro-vida VITAM en el proceso judicial C.C.A. estuvo destinada a impedir la práctica del aborto no punible en el sistema de salud. Y de la misma forma que la presentación de la Corporación de Abogados Católicos, esta ONG pro-vida era ajena al proceso judicial, invocó la defensa de la persona por nacer y se inscribió en el discurso de los derechos humanos, especialmente los que protegen los derechos de los niños, niñas y adolescentes, y el derecho a la vida. Si bien esta ONG pro-vida obtuvo respuestas favorables en los tribunales provinciales inferiores, no obtuvo una respuesta favorable de la Suprema Corte de Justicia de la provincia de Mendoza.

En el año 2010, otra presentación de una ONG pro-vida tuvo como propósito intimidar a jueces que habilitaron la realización de un aborto no punible en los servicios de salud. Concretamente, el abogado de la ONG pro-vida, Grávida, también presidente del Colegio de Abogados de la ciudad de Bariloche en la provincia de Río Negro, promovió un proceso para destituir a un juez que había autorizado la práctica de un aborto no punible a una joven embarazada producto de un abuso sexual. En este caso, a diferencia de los anteriores, la denuncia estuvo destinada a aplicar una medida disciplinar a un integrante de la institucionalidad judicial, tuvo fuertes resistencias de otros miembros del
14. Denuncia presentada por el abogado católico ante el Juzgado de Garantías. 9 de febrero del 2007, pp. 1-21 del expediente judicial.
15. El amparo es un proceso judicial rápido. Fue incorporado en la Reforma Constitucional de 1994.

16. SCJ Mendoza, «G., A.R. en C., S.M. y otros», sentencia del 22 de agosto del 2006, La Ley 2006-E, 171.

17. Después del fallo de la Suprema Corte de Justicia de la provincia de Mendoza que habilitó a la joven embarazada a realizarse la práctica de aborto no punible, el hospital en donde debía realizarse la práctica recibió llamadas telefónicas intimidatorias de grupos antiabortistas religiosos con amenazas a profesionales de la salud. Asimismo, hubo amenaza de bomba en el hospital. Documentos de prensa escrita de fecha 23 de agosto del 2006. 
18. CSJN, «Pro Familia Asociación Civil c/ GBCA y otros s/impugnación de actos administrativo», sentencia del 11 de octubre del 2012, La Ley 2013-A, 103.
Colegio de Abogados que cuestionaron el uso abusivo del proceso de destitución, y no repercutió en la práctica del aborto no punible.

Finalmente, en el año 2012, el abogado de la ONG pro-vida Por Familia se constituyó como «abogado del niño» en un proceso judicial en la ciudad de Buenos Aires, y solicitó una medida judicial para impedir la práctica del aborto no punible a una mujer que ese año había sido rescatada de una red de trata de personas, y cuya situación trascendió en los medios de prensa. ${ }^{18} \mathrm{La}$ solicitud del abogado fue rechazada en los tribunales inferiores, así como en la Cámara de Apelaciones y, en tanto, la reiteró en otro juzgado que aceptó la medida solicitada y ordenó la suspensión de la práctica. Esta doble judicialización conservadora llegó a la Corte Suprema de Justicia de la Nación que revocó la medida, y ordenó a las autoridades que garanticen la realización de aborto. ${ }^{18}$

Las intervenciones de ONGs y abogados pro-vida en procesos judiciales en los que niñas, jóvenes y mujeres demandaban el acceso a las prácticas de aborto no punible en el sistema de salud, entonces, implicaron presentaciones ante las cortes para solicitar a los tribunales que obstruyan, impidan o criminalicen las prácticas de aborto no punible. En todos los procesos judiciales, estas presentaciones sucedieron con posterioridad a que las instituciones sanitarias y/o judiciales dispusieran garantizar el acceso a la práctica del aborto no punible. De esta forma, la judicialización supuso un uso reactivo del derecho para sostener al aborto no punible como una práctica prohibida en el marco de la institucionalidad estatal.

Asimismo, es posible advertir que las presentaciones de ONGs y abogados pro-vida en procesos judiciales estuvieron acompañadas por otras estrategias en las instituciones sanitarias, en otras instituciones estatales y en los medios de prensa. En el marco de los procesos judiciales, las ONGs y abogados pro-vida ejercieron presiones personales, políticas y jurídicas sobre las niñas, jóvenes y mujeres, sus familiares y su entorno social, sobre los profesionales de la salud y/o sobre funcionarios públicos intervinientes para obstaculizar e impedir la práctica del aborto no punible en el sistema de salud. Además, estas estrategias jurídicas fueron sostenidas mediante la exposición de los procesos judiciales en los medios de prensa.

La judicialización de las ONGs y abogados pro-vida fueron apoyadas por otras organizaciones, instituciones y ciudadanos; y tuvieron diferentes efectos en las decisiones judiciales y de profesionales de la salud de instituciones sanitarias. De forma general, es posible advertir que las decisiones judiciales fueron desfavorables para las ONG pro-vida en los tribunales superiores provinciales y en la Corte Suprema de Justicia de la Nación, lo que generó una jurisprudencia que resolvió gradualmente asuntos relacionados con el acceso a la práctica del aborto no punible en el país. Sin embargo, a pesar de que los tribunales garantizaron la vigencia de los abortos no punibles, las instituciones sanitarias tendieron a mantener su resistencia en garantizar la práctica. 
Estas intervenciones situadas en las cortes tuvieron como punto de inflexión el proceso judicial del año 2010 resuelto por la Corte Suprema de Justicia de la Nación en el año 2012, F., A.L., en el que la Corte definió cuestiones relacionadas con la extensión, la constitucionalidad y la convencionalidad de la regulación jurídica del aborto, consideró el contexto de obstrucción e impedimento de acceso a la práctica en el sistema de salud, y exhortó a los gobiernos nacional y provinciales a dictar protocolos de atención de abortos no punibles que garanticen el acceso seguro a la práctica en el sistema de salud. Como desarrollamos a continuación, esta sentencia abrió otra etapa diferenciada de la judicialización conservadora.

\section{Impugnación de protocolos de atención de abortos no punibles}

En el año 2010 tomó trascendencia en los medios de prensa el proceso judicial F., A.L. en el que una joven embarazada como producto de un abuso sexual, A.G., obtuvo una sentencia favorable del Superior Tribunal de Justicia de Chubut para realizarse un aborto no punible. A pesar de que la joven pudo realizarse la práctica, el proceso judicial $F$., $A$. L. llegó a la Corte Suprema de Justicia de la Nación. ONGs y abogados pro-vida presentaron amicus curiae ante la Corte para solicitar el rechazo de esta sentencia. En el año 2012, la Corte resolvió este proceso judicial y se pronunció sobre la extensión, la constitucionalidad y la convencionalidad de la regulación jurídica del aborto, sobre las prácticas médicas y judiciales de obstrucción e impedimento de las prácticas de aborto no punible, sobre las condiciones de acceso a la práctica del aborto en el sistema de salud, y sobre la responsabilidad del Estado.

La Corte Suprema, además, exhortó a los gobiernos nacional y provinciales a que aprueben protocolos de atención de abortos no punibles a fin de eliminar obstáculos al aborto no punible en el sistema de salud. Como efecto a este fallo, diferentes provincias y la ciudad de Buenos Aires aprobaron protocolos de atención de abortos no punibles. ${ }^{19}$ Esto provocó una mutación de los asuntos que llegaron a los tribunales puesto que, tras la aprobación de protocolos de abortos no punibles, los procesos judiciales recayeron, en su mayoría, sobre estos instrumentos que fueron cuestionados. ONGs y abogados pro-vida iniciaron procesos judiciales a través de los que impugnaron los protocolos de atención de abortos no punibles. ${ }^{20}$

Una de las ONGs pro-vida que inició la judicialización conservadora de protocolos de atención de abortos no punibles fue Portal de Belén. Esta organización fue fundada en 1987, y se constituyó como asociación civil en 1994. En su estatuto establece que la finalidad de la asociación es la «defensa del derecho pleno a la vida» y el "respeto a la dignidad de la persona humana desde el momento de su concepción», apoyar a las «mujeres embarazadas en situación de conflicto», apoyar a las «mamás solas en situación de conflicto para que consoliden la relación con sus hijos» y promover y defender «el establecimiento de las condiciones sociales que posibiliten y favorezcan la efectiva protección del derecho a la vida desde el momento de la concepción y el
19. Algunas actualizaron o aprobaron protocolos a través de sus ejecutivos, ministerios de salud o legislaturas provinciales y otras adhirieron a la Guía Técnica Nacional que, hasta el 2012, tenía una última actualización del año 2010 del Ministerio de Salud Nacional.

20. En el año 2008, la ONG pro-vida Pro Familia inició un proceso judicial en los tribunales de la ciudad de Buenos Aires para pedir la nulidad del protocolo que establecía el procedimiento para la atención del aborto no punible en el sistema de salud. Este proceso judicial fue atípico previamente al fallo de la Corte Suprema en F., A.L. 
21. CSJN, «Portal de Belén Asociación Civil sin Fines de Lucro c/ Ministerio de Salud y Acción Social de la Nación s/ amparo», sentencia del 5 de marzo del 2002.

22. Demanda de amparo presentada por Portal de Belén ante los tribunales de la provincia de Córdoba, pp. 9697 del expediente judicial.

23. Esto es, los efectos de las sentencias comprenden a grupos sociales no involucrados directamente en el proceso judicial pero cuyos intereses se encuentran comprometidos en el proceso judicial.

24. Amicus curiae presentado por Ojo Ciudadano ante el Tribunal Superior de Justicia de la provincia de Córdoba, $p$. 1571 del expediente judicial. goce del respeto a su dignidad intrínseca a lo largo de su vida» (Estatuto de la organización Portal de Belén).

En 1998, la organización Portal de Belén inició un proceso judicial contra la fabricación, distribución y comercialización del fármaco «Imediat» (también conocido como la «píldora del día después»), que fue resuelto favorablemente por la Corte Suprema de Justicia de la Nación en el 2002. ${ }^{21}$ Asimismo, esta organización realizó presentaciones en procesos judiciales para oponerse a las solicitudes de autorización judicial para contraer matrimonio que realizaron parejas del mismo sexo, por ejemplo. Tras el fallo de la Corte Suprema sobre aborto no punible en el año 2012, la provincia de Córdoba aprobó un protocolo de abortos no punibles, e inmediatamente después Portal de Belén inició un proceso judicial para solicitar la suspensión de la aplicación de este protocolo. Para fundamentar su presentación, la organización invocó su trayectoria en la protección de mujeres desamparadas, y del derecho a la vida.

Según Portal de Belén, la aplicación del protocolo justifica su intervención en defensa del derecho a la vida humana desde el momento de la concepción, puesto que la "persona por nacer no puede actuar por sí misma», su representante legal (la madre) es quien «pretende quitarle la vida», y «quien les quita la vida» es el Estado, puesto que el protocolo obliga a profesionales de la salud a "matar a un número indeterminado de personas». ${ }^{22}$ Sostuvo, además, que el amparo permite la defensa de derechos de incidencia colectiva, y la obtención de sentencias erga omnes ${ }^{23}$ [contra todos]. Según la organización, por la aplicación del protocolo serían «matados millares de niños» y, por lo tanto, sería violada la garantía constitucional de «la vida de todo ser humano "desde el momento de su concepción"». ${ }^{22}$

El tribunal de primera instancia resolvió suspender parcialmente la aplicación del protocolo de atención de abortos no punibles. Esta decisión fue confirmada por la Cámara de Apelaciones y recurrida ante el Tribunal Superior de Justicia de la provincia de Córdoba por las partes involucradas en el proceso. Este proceso trascendió en los medios de prensa, y las resoluciones de los tribunales generaron incertidumbre respecto de las formas en que el Estado garantiza el acceso a la práctica del aborto no punible en la provincia de Córdoba. Actualmente se encuentra pendiente de resolución ante el Tribunal Superior a donde se presentaron amicus curiae de ONGs pro-vida como Ojo Ciudadano, que se presentó en defensa de la «vida desde el momento de la concepción»; ${ }^{24}$ y de legisladores del poder legislativo de la provincia de Córdoba.

En este proceso judicial, la organización pro-vida invocó la protección de la persona por nacer y fundó la presentación en el discurso de los derechos humanos, especialmente los que protegen el derecho de niñas, niños y adolescentes, y el derecho a la vida; y retomó el principio pro-homine. El discurso de los derechos humanos, en tanto reflejo de una verdad natural trasnacional, atraviesa la presentación de la organización Portal de Belén en las cortes y fundamenta la criminalización del aborto. El otro discurso que fundamenta la criminalización total del aborto es el del derecho a la vida. De acuerdo con Portal de Belén, la no punibilidad del aborto es un permiso para matar, y los 
fundamentos de esa permisión responden a una ideología eugenésica vigente al momento de sanción del código penal (principios del siglo XX).

El proceso judicial iniciado por Portal de Belén pone de manifiesto otra forma de imbricación entre lo jurídico y lo religioso. Los fundamentos dados en el proceso judicial imbrican aspectos seculares y religiosos a través del uso del discurso de los derechos humanos, tomados como reflejo de una ley natural y de una moral sexual universal y objetiva. Este tipo de discursos, en consonancia con lo dispuesto por la Iglesia Católica, si bien se desplaza hacia un discurso de derecho secularizado, reinscribe el posicionamiento dogmático de la doctrina católica sobre la sexualidad y reproducción.

En un sentido similar al proceso judicial iniciado por Portal de Belén durante el año 2012 fueron iniciados otros procesos judiciales para impugnar los protocolos de atención de abortos no punibles. El Partido Demócrata Cristiano en la provincia de Santa Fe, integrantes de la agrupación Pro Vida en la provincia de Entre Ríos, y el abogado Francisco Durand Casali en la provincia de Salta, y obtuvieron respuestas disímiles en los tribunales de esas provincias. En el 2013, una legisladora en la provincia de Tucumán inició un proceso judicial para solicitar al gobierno que se abstenga de aplicar protocolos de atención de abortos no punibles.

Al igual que las presentaciones de ONGs y abogados pro-vida en los procesos judiciales de aborto no punible en los que niñas, jóvenes y mujeres reclamaban el acceso a la práctica del aborto no punible, la judicialización conservadora de los protocolos de atención de abortos no punibles es reactiva a la política que habilitó el avance en la aprobación de estos protocolos, fue en defensa de la persona por nacer y estuvo mayoritariamente fundada en el discurso de los derechos humanos. Sin embargo, resulta necesario destacar que una diferencia crucial es que los resultados de los procesos judiciales destinados a impugnar protocolos de atención de abortos no punibles, al afectar regulaciones jurídicas procedimentales, alcanzan a un amplio grupo de personas y comprometen la prestación del servicio de salud.

Estas presentaciones de ONGs y abogados pro-vida en procesos judiciales de aborto no punible, entonces, fueron constitutivas de una judicialización conservadora reactiva destinada a expandir la criminalidad de la regulación jurídica del aborto, así como a obstruir, impedir y criminalizar la práctica del aborto e impedir la aplicación de los instrumentos de procedimientos para la realización del aborto no punible en el sistema de salud.

\section{Reflexiones finales}

El derecho, como dijimos, es un sitio de disputa privilegiada en los debates contemporáneos sobre las formas de regular la sexualidad y la reproducción. Por un lado, los movimientos feministas y LGBTI defienden un paradigma de 
derechos que busca desmontar la influencia de la moral católica sobre la regulación jurídica. Por otro lado, la jerarquía católica y sectores aliados se movilizan en defensa de un modelo imbricado que solapa doctrina religiosa, moral sexual y derecho secular.

Precisamente, en este artículo indagamos de qué forma las ONGs y abogados pro-vida defendieron, a través de presentaciones en procesos judiciales de aborto no punible, la imbricación de la moral religiosa con el derecho secular. Focalizamos en las intervenciones de ONGs y abogados pro-vida en procesos judiciales de aborto no punible, asumiendo que la apelación a las cortes para dirimir asuntos políticos constituye un proceso de judicialización conservadora con diferentes matices. Incrementalmente desde el año 2005, año en que se conformó la Campaña Nacional por el Derecho al Aborto Legal, Seguro y Gratuito, la judicialización fue mutando y tuvo dos momentos diferenciables debido a los efectos de la sentencia de la Corte Suprema de Justicia de la Nación en F., A.L. del año 2012, aunque mantienen algunas similitudes a lo largo del tiempo.

En un primer momento de la judicialización conservadora, desde el año 2006 hasta el año 2012, las presentaciones de las ONGs y abogados pro-vida en procesos judiciales tuvieron como propósito, con escasas excepciones, obstruir, impedir o criminalizar prácticas de aborto no punible de niñas, jóvenes y mujeres en el sistema de salud. En este primer momento, la judicialización conservadora buscó evitar la existencia de abortos no punibles, es decir, abortos permitidos por la legislación vigente, como forma de defender la imbricación entre derecho y moral religiosa. Como vimos, para el magisterio de la Iglesia Católica, el aborto voluntario es siempre contrario al derecho natural. La judicialización conservadora buscó clausurar la posibilidad de abortos amparados por el derecho como defensa a la doctrina católica, es decir, buscó reinscribir los principios morales religiosos a través de las prácticas jurídicas.

En el segundo momento hubo una mutación en las intervenciones de ONGs y abogados pro-vida situadas en las cortes que, mayoritariamente, estuvieron destinadas a impugnar los protocolos de atención de abortos no punibles recientemente aprobados. Desde el año 2012, entonces, las presentaciones de las ONGs y abogados pro-vida en procesos judiciales de aborto no punible tuvieron como propósito, con escasas excepciones, suspender, modificar $o$ anular protocolos de atención de abortos no punibles. Si en la primera etapa la judicialización reactiva era para impedir que niñas, jóvenes y mujeres pudieran efectuar sus abortos, en este segundo momento las intervenciones viran para impugnar regulaciones procedimentales sobre aborto no punible que afectan de forma general a personas con capacidad de gestar.

Si bien estos procesos judiciales tienen finalidades diferentes e impactan de manera diferenciada en las prácticas de aborto no punible, es posible advertir algunas similitudes. En todos estos procesos judiciales las intervenciones de las ONGs y los abogados pro-vida sostuvieron una imbricación entre lo religioso y el derecho, fundadas en la protección de la persona por nacer y, mayoritariamente, inscripta en el discurso de los derechos humanos, especial- 
mente en aquellos instrumentos que protegen la vida, niños, niñas y adolescentes. La inscripción en el discurso de los derechos humanos es un patrón de estas intervenciones en procesos judiciales de aborto no punible.

Un rasgo transversal de intervenciones de las ONGs y los abogados pro-vida en los procesos judiciales de aborto no punible, como vimos, es que son reactivas a las políticas que los habilitan, en su mayoría políticas feministas. Estas intervenciones constituyeron un proceso de judicialización conservadora reactiva que pretende obstruir e impedir las prácticas de aborto no punible e impugnar las reglamentaciones que las habilitan. Los procesos judiciales, como sitios de disputas, permitieron (re)inscribir un orden sexual conservador en las prácticas sexuales a través del derecho.

En estos procesos judiciales, entonces, hubo un «contra-uso» del derecho (Smart 1989, 39), destinado a instituir una política sexual a través de las prácticas jurídicas situadas en la institucionalidad estatal judicial. Esta política sexual conservadora además de defender una sexualidad anudada a sus (eventuales) consecuencias reproductivas busca también que el derecho (secular) proteja la moral religiosa, produciendo de esta forma una doble sujeción: de la sexualidad a la reproducción y del derecho a la moral religiosa.

\section{Bibliografía}

Anzorena, Claudia y Ruth Zurbrigge. 2013. «Trazos de una experiencia de articulación federal y plural por la autonomía de las mujeres: la Campaña Nacional por el Derecho al Aborto Legal, Seguro y Gratuito en Argentin». En El aborto como derecho de las mujeres. Otra historia es posible, editado por Ruth Zurbriggen y Claudia Anzorena, 17-38. Buenos Aires: Herramienta.

Asad, Talal. 2003. Formations of the Secular. Christianity, Islam and Modernity. Palo Alto: Standford University Press.

Benente, Mauro. 2015. "Lecturas sobre gubernamentalidad, biopolítica y derecho». En Michel Foucault. Derecho y poder, editado por Mauro Benente. Buenos Aires: Didot.

Bergallo, Paola. 2011. «La liberalización del aborto: contextos, modelos regulatorios y argumentos para su debate». En Aborto y justicia reproductiva, editado por Paola Bergallo, 1-57. Buenos Aires: Del Puerto.

Casanova, José. 1994. Public Religions in the Modern World. Chicago: The University of Chicago.

Connolly, William E. 1999. Why I am not a secularist. Minneapolis: University of Minnesota Press. 
Domingo, Pilar. 2009. «Ciudadanía, derechos y justicia en América Latina: ciudadanización-judicialización de la política». Revista CIDOB d'afers internacionals 85/86: 33-52.

Douzinas, Costas. 2000. The End of Human Rights. Oxford: Hart Publishing.

Foucault, Michel. 1970. El orden del discurso. Traducción de Alberto González Troyano, 1992. Buenos Aires: Tusquets.

García Romanutti, Hernán. 2015. «El derecho entre dominación y resistencia. Una concepción estratégica de lo jurídico a partir de Michel Foucault». En Michel Foucault. Derecho y poder, editado por Mauro Benente. Buenos Aires: Didot.

González Prado, Patricia. 2011. «Cuerpos tomados, cuerpos reapropiados: Obstáculos al aborto no punible. Análisis de casos en Argentina desde una lectura feminista». Barcelona: Universidad Autónoma de Barcelona.

González Ruiz, Edgar. 2006. Cruces y sombras. Perfiles del conservadurismo en América Latina. San José: Colectiva por el Derecho a Decidir.

Jakobsen, Janet R. y Anne Pellegrini. 2004. Love the Sin. Sexual Regulation and the Limits of Religious Tolerance. Boston: Beacon.

Monte, María Eugenia. 2015. «Abortion liberalization demand in Argentina: legal discourses as site of power struggle. A case study on the structural case Portal de Belen vs. Cordoba (2012-2013)». Oñati Socio-Legal Series 5 (5): 1261-90.

Monte, María Eugenia. 2017. «Abortion, Sexual Abuse and Medical Control: The Argentinian Suprem Court Decision on F., A.L.» Sexualidad, Salud y Sociedad, Revista Latinoamericana, n. ${ }^{\circ} 26:$ 68-84.

Morán Faúndes, José Manuel. 2015. «El desarrollo del activismo autodenominado "Pro-Vida" en Argentina, 1980-2014». Revista Mexicana de Sociología 77 (3): 407-35.

Morán Faúndes, José Manuel, María Eugenia Monte, Laura Judith Sánchez, y Raquel Irene Drovetta. 2011. "La inevitable maternidad. Actores y argumentos conservadores en casos de aborto no punible en Argentina». En Actores y discursos conservadores en los debates sobre sexualidad y reproducción en la Argentina, editado por María Angélica Peñas Defago y Juan Marco Vaggione, 127-56. Córdoba: Ferreyra.

Morán Faúndes, José Manuel, María Angélica Peñas Defago, María Eugenia Monte, y María Candelaria Sgró Ruata. 2015. "Sociedad civil y sexualidad: las ONG autodenominadas "pro-vida"». En Permeabilidades activas. Religión, política y sexualidad en la Argentina democrática, editado por Juan Cruz Esquivel y Juan Marco Vaggione, 35-54. Buenos Aires: Biblos. 
Mujica, Jaris. 2007. Economía política del cuerpo. La reesctructuración de los grupos conservadores y el biopoder. Lima: Promex.

Munro, Vanessa E. 2001. "Legal feminism and Foucault. A critique of the expulsion of law». Journal of law and society 28 (4): 546-67.

Munro, Vanessa E. 2007. Law and politics ate the perimeter. Re-evaluating key debates in feminist theory. Oxford: Hart Publishing.

Peñas Defago, María Angélica, y José Manuel Morán Faúndes. 2014. "Conservative litigation against sexual and reproductive health policies in Argentina». Reproductive Health Matters 22 (44): 82-90.

Smart, Carol. 1989. Feminism and the power of law. New York: Routledge.

Smart, Carol. 1992. "The woman of legal discourse». Social \& Legal studies. An international journal 1: 29-44.

Sullivan, Winnifred Fallers, Robert Yelle, y Mateo Taussig-Rubio. 2013. «Introduction». En After a Secular Law, editado por Winnifred Fallers Sullivan, Robert Yelle, y Mateo Taussig-Rubio, University Press Scholarship Online.

Vaggione, Juan Marco. 2005. «Reactive politicization and religious dissidence: the political mutations of the religious». Social theory and practice 31 (2): 233-55.

Vaggione, Juan Marco. 2012. «Introducción». En Sexualidades, desigualdades $y$ derechos. Reflexiones en torno a los derechos sexuales y reproductivos, editado por José Manuel Morán Faúndes, Candelaria Sgró Ruata, y Juan Marco Vaggione. Córdoba: Ciencia, Derecho y Sociedad.

Vaggione, Juan Marco. 2016. «Sexualidad, derecho y religión: entramados en tensión». En Sexo, delitos y pecados. Intersecciones entre religión, género, sexualidad y el derecho en Amércia Latina, editado por Macarena Sáez y José Manuel Morán Faúndes, 17-51. Washington: Center For LAatin American \& Latino Studies, American University. 